(n)

\title{
Regulation of P21 during diabetes- associated stress of the endoplasmic reticulum
}

\author{
Chrysovalantou Mihailidou', Ioulia Chatzistamou ${ }^{2,3}$, Athanasios G Papavassiliou' \\ and Hippokratis Kiaris ${ }^{1,4}$
}

'Department of Biological Chemistry, University of Athens Medical School, Athens 11527, Greece

${ }^{2}$ Department of Basic Sciences, Dental School, University of Athens, Athens 11527, Greece

${ }^{3}$ Department of Pathology, Microbiology and Immunology, University of South Carolina School of Medicine, Columbia, South Carolina 29208, USA

${ }^{4}$ Department of Drug Discovery and Biomedical Sciences, University of South Carolina, Columbia,

South Carolina 29425, USA

\author{
Correspondence \\ should be addressed \\ to H Kiaris \\ Email \\ kiarish@sccp.sc.edu
}

\begin{abstract}
Endoplasmic reticulum (ER) stress plays a major role in the pathogenesis of diabetes by inducing $\beta$-cell apoptosis in the islets of Langerhans. In this study, we show that the transcription factor CHOP, which is instrumental for the induction of ER-stress-associated apoptosis and the pancreatic dysfunction in diabetes, regulates the expression of P21 (WAF1), a cell cycle regulator with anti-apoptotic activity that promotes cell survival. Deficiency of P21 sensitizes pancreatic $\beta$-cells to glucotoxicity, while in mice genetic ablation of P21 accelerates experimental diet-induced diabetes, results indicative of a protective role for P21 in the development of the disease. Conversely, pharmacological stimulation of P21 expression by nutlin-3a, an inhibitor of P53-MDM2 interaction, restores pancreatic function and facilitates glucose homeostasis. These findings indicate that P21 acts as an inhibitor of ER-stress-associated tissue damage and that stimulation of P21 activity can be beneficial for the management of diabetes and probably of other conditions in which ER-stress-associated death is undesirable.
\end{abstract}

\section{Key Words}

- unfolded protein response

- glucotoxicity

- glucose

- chaperone

- $\beta$ cells
Endocrine-Related Cancer (2015) 22, 217-228

\section{Introduction}

The accumulation of unfolded and misfolded proteins in the endoplasmic reticulum (ER) causes stress which is toxic to the cells and may compromise normal tissue function (Ron \& Walter 2011). Cells respond to ER stress by initiating a biochemical response that is designated as the unfolded protein response (UPR). UPR at its early stages or during mild ER stress is pro-survival and adaptive, aiming to restore cellular homeostasis through mechanisms involving elevated chaperone production and inhibition of protein translation (Ron \& Walter 2011). However, when cellular homeostasis is not restored, such as when ER stress is excessive or intensive, UPR becomes pro-apoptotic, clearing the cells in which ER stress is deemed unresolvable (Ron \& Walter 2011).

ER stress has been implicated in the pathogenesis of various diseases, including diabetes, in which the increased demands for insulin production and secretion induce ER stress in the insulin-producing pancreatic $\beta$-cells (Back \& Kaufman 2012). Ultimately, the $\beta$-cells die of ER-stress-associated death, compromising overall pancreatic function and glucose homeostasis (Back \& Kaufman 2012). The transcription factor CHOP, a member of the CCAAT-enhancer-binding proteins (C/EBP) family of bZIP transcription factors, plays an instrumental role in

Published by Bioscientifica Ltd. 
the execution of ER-stress-associated apoptosis (Zinszner et al. 1998, Oyadomari \& Mori 2004, Puthalakath et al. 2007). In the context of diabetes, genetic ablation of $\mathrm{CHOP}$ results in resistance to the disease through molecular mechanisms associated with the promotion of $\beta$-cell survival in pancreatic Langerhans' islets, an observation that underlines the significance of $\mathrm{CHOP}$-induced apoptosis in the pathogenesis of diabetes (Oyadomari et al. 2002, Ron 2002).

While the mechanisms governing ER-stress-associated apoptosis have been extensively studied, the transition from the adaptive to the pro-apoptotic function of the UPR remains poorly understood. Results from recent studies have provided evidence that the expression of P21 exhibits an inverse correlation with ER-stress induction and CHOP expression (Mihailidou et al. 2010). This result is indicative of a role for this cell cycle regulator in the commitment of the UPR to the adaptive or the proapoptotic program that follows ER stress (Mihailidou et al. 2010, Yi et al. 2012, Mlynarczyk \& Fåhraeus 2014). P21 is a cell cycle regulator that in addition to the inhibition of cell cycle progression also exhibits strong anti-apoptotic activities that can affect the decision about life or death of a cell under conditions associated with genotoxic stress (Blagosklonny 2002, Roninson 2002, Weiss 2003, Trimis et al. 2008). In this study, we examined the mechanism through which P21 levels are regulated during ER stress, and explored the biological relevance of our findings in the context of diabetes.

\section{Materials and methods}

\section{Cell culture and transfections}

HIT-T15 cells (a hamster pancreatic islet $\beta$-cell line) were acquired from the American Type Culture Collection (ATCC, Manassas, VA, USA). HIT-T15 cells were cultured with Ham's F12K (Kaighn's) medium supplemented with $10 \%$ horse serum (ATCC) and $2.5 \%$ fetal bovine serum and penicillin/streptomycin at $37^{\circ} \mathrm{C}$ in a humidified atmosphere of $5 \% \mathrm{CO}_{2} 95 \%$ air. The passage range of the HIT cells used was 61-70. Before experiments were performed, the culture medium of HIT-T15 cells was replaced with extracellular Krebs-Ringer (KR) solution (Sigma-Aldrich).

HIT-T15 cells were transfected by using Thermo Scientific (Waltham, MA, USA) TurboFect Transfection Reagent. Tunicamycin (Tun), doxorubicin (DOX), and nutlin-3a $(\mathrm{Nu})$ were obtained from Sigma-Aldrich and treatment conditions are described in the 'Results' section and in the corresponding figure legends.

\section{Western blot assays}

Whole cells, islets, and tissue lysates were prepared in RIPA buffer (Sigma-Aldrich) and were subjected to immunoblot analysis by standard methods. The primary antibodies used were GADD153 (F-168), sc-575 from Santa Cruz Biotechnology (1:50); P53 (C-19), sc-1311 from Santa Cruz Biotechnology (1:500); P21 (F-5), sc-6246 from Santa Cruz Biotechnology (1:200); actin, clone C4 MAB1501 from Millipore (Billerica, MA, USA) (1:2000); BiP antibody (cat. no. 3183) from Cell Signaling (Danvers, MA, USA) (1:1000); GRP94 antibody (H-212), sc-11402 from Santa Cruz Biotechnology (1:500); insulin rabbit polyclonal H-86, sc-9168 from Santa Cruz Biotechnology (1:500).

\section{Islet isolation and determination of islet viability}

Pancreatic islets were manually isolated from female C57BL/6 and $P 21 \mathrm{KO}$ mice by the collagenase digestion method (Sigma-Aldrich; Li et al. 2009). The viability of the islets was determined using the colorimetric (3-(4,5dimethylthiazol-2-yl)-2,5-diphenyltetrazolium bromide assay using the CellTiter 96 Non-radioactive Cell Proliferation Assay Kit (Promega; Janson et al. 1996).

\section{P21 ${ }^{\text {Cip1 }}$ reporter plasmids and luciferase activity assays}

A $0.7 \mathrm{~kb}$ fragment spanning the CCAAT site at $-683 \mathrm{bp}$ upstream of the translation initiation site of the P21 gene was PCR-amplified from normal mouse genomic DNA with primers 5'-GGGGTACCCCGCATGTGACAAT CAACTT - $3^{\prime}$ and 5'-CCGCTCGAGCGGGACACATTTCCCCACGAAGT-3' and cloned into pGL3 Basic (Promega) luciferase reporter plasmid. Reporter assays were performed using the Dualluciferase Reporter Assay System Firefly and Renilla Luciferase Assay Kit (Biotium, Hayward, CA, USA; cat. no. 30003-1) at $24 \mathrm{~h}$ after transfection, according to the manufacturer's protocol. The results were normalized by performing co-transfection with a plasmid constitutively expressing Renilla luciferase. The results indicated are expressed in relative luciferase units and are representative of at least three independent experiments carried out in triplicates, with s.D.s between experiments shown in the form of error bars.

\section{Clonogenic survival assay}

After cells were cultured in media with normal and high $(25 \mathrm{mM})$ levels of glucose for $24 \mathrm{~h}$, were trypsinized, washed, diluted $1 / 10$, and seeded into $100 \mathrm{~mm}$ dishes in media. The cells were grown for 2-3 weeks and colonies

Published by Bioscientifica Ltd 
were fixed with methanol:acetic acid (3:1) and stained with hematoxylin (10\% Mayer's hematoxylin), and counted. At least three different experiments were carried out in triplicate for each cell line.

\section{Measurements of caspase activity}

About 100 islets of similar size were washed in RPMI-1640 medium with $10 \%$ FCS and pre-incubated in basal glucose $(3.3 \mathrm{mM})$ for $1 \mathrm{~h}$ at $37^{\circ} \mathrm{C}$ in KR bicarbonate HEPES buffer containing $129 \mathrm{mM} \mathrm{NaCl}, 5 \mathrm{mM} \mathrm{NaHCO} 3,4.8 \mathrm{mM}$ $\mathrm{KCl}, 1.2 \mathrm{mM} \mathrm{MgSO}_{4}, 1.2 \mathrm{mM} \mathrm{KH_{2 }} \mathrm{PO}_{4}, 1.0 \mathrm{mM} \mathrm{CaCl}$, and $10 \mathrm{mM}$ HEPES at pH 7.4, plus 0.1\% RIA-grade BSA (Sigma-Aldrich). After this static incubation, a stimulatory incubation was performed using media with high levels of glucose $(25 \mathrm{mM})$ for $24 \mathrm{~h}$. The supernatants were collected for caspase assays. The caspase assays were performed using a Caspase Colorimetric Protease Assay KHZ1001 (Invitrogen) according to the manufacturer's protocol.

\section{Determination of insulin secretion}

Blood samples $(1 \mathrm{ml})$ were collected in $1.5 \mathrm{ml}$ EDTA-coated Eppendorf tubes, centrifuged at $1200-1500 \mathrm{~g}, 4^{\circ} \mathrm{C}$ for $10 \mathrm{~min}$. The supernatant (serum) was transferred into $1.5 \mathrm{ml}$ Eppendorf tubes and stored at $-80{ }^{\circ} \mathrm{C}$ for insulin analysis. Serum insulin levels were determined using the Ultra Sensitive Mouse Insulin ELISA Kit (Crystal Chem, Inc., Downers Grove, IL, USA) in accordance with the manufacturer's guidelines.

\section{Histological analysis and immunohistochemistry}

Tissue samples were fixed at $4 \%$ buffered formalin, embedded in paraffin wax, cut into $4 \mu \mathrm{m}$ sections, and stained with hematoxylin and eosin. Insulin was detected with rabbit polyclonal antibody H-86 (Santa Cruz Biotechnology, SC-9168; dilution 1:50) using a SuperPicture Polymer Detection Kit (Life Technologies). The islet area was evaluated in insulin-stained sections of the pancreas from at least three mice per genotype per treatment by using the ImageJ Software (NIH, Bethesda, MD, USA). Data are mean values \pm s.E.M. of three mice per genotype per treatment.

\section{Determination of glucose level and intraperitoneal insulin tolerance test}

The glucose levels of mice were measured using an Accu-Chek Active Meter (Roche) with blood sample obtained from the tail vein after 6 - $\mathrm{h}$ fasting. For glucose tolerance, mice received i.p. injections of $2 \mathrm{~g}$ glucose/kg body weight (BW). The blood samples were taken from tail vein. For the insulin resistance test, mice received i.p. injections of human insulin $(0.75 \mathrm{U} / \mathrm{kg}$ BW; Sigma-Aldrich) and blood glucose was measured.

\section{Mouse strains}

Mice were originally obtained from The Jackson Laboratory (Bar Harbor, ME, USA). All mice were housed under specific-pathogen-free conditions, according to Animal Facilities recommendations. The first group of $\mathrm{C} 57 \mathrm{Bl} / 6$ mice and P21-knockout mice, 4-5 weeks old, were provided with either a solution of $10 \%$ sucrose and a diet containing $40 \% \mathrm{kcal}$ as a high-fat diet (HFD; Open Source Diets (New Brunswick, NJ, USA) D12451, 40\% calories/fat) with free access to (10\%) sweetened water (sucrose) or a standard chow diet containing 10\% of kcal as fat (low-fat diet) and drinking water with no added sucrose (control). The second group of C57Bl/6 mice of 4-5 weeks old became diabetic as a result of standard administration of a combination of a low-dose of streptozotocin (STZ), $50 \mathrm{mg} / \mathrm{kg}$ daily, prepared freshly in $0.1 \mathrm{~mol} / \mathrm{l}$ citrate buffer, $\mathrm{pH}$ 4.0, for 5 consecutive days i.p. and a HFD.

\section{Statistical analysis}

All data were analyzed by Student's $t$-test and results were considered to be significant if $P<0.05$.

\section{Results}

P21 expression inversely correlates with UPR induction during glucose-associated ER stress in $\beta$-cells

Earlier observations at our laboratory indicated that pharmacological induction of ER stress, by the inhibitor of protein glycosylation Tun, is associated with a progressive suppression of P21 expression (Mihailidou et al. 2010). In order to test the relevance of this observation to pancreatic $\beta$-cell physiology, we investigated whether ER stress triggered by abnormal glucose levels in the culture media also affects the P21 levels in $\beta$-cells. Both high (glucotoxicity) and low (deprivation) glucose concentrations are established activators of the UPR in cells exposed to these conditions (Xu et al. 2005, Fonseca et al. 2011, Moore et al. 2011, Palorini et al. 2013). Indeed, culture of pancreatic Syrian hamster-derived HIT-T15 insulinoma cells with low or high concentrations of glucose inhibited P21 expression (Fig. 1A). Under these conditions, the induction of ER stress was confirmed by the increased stimulation of the expression of the chaperones GRP94 and

Published by Bioscientifica Ltd. 


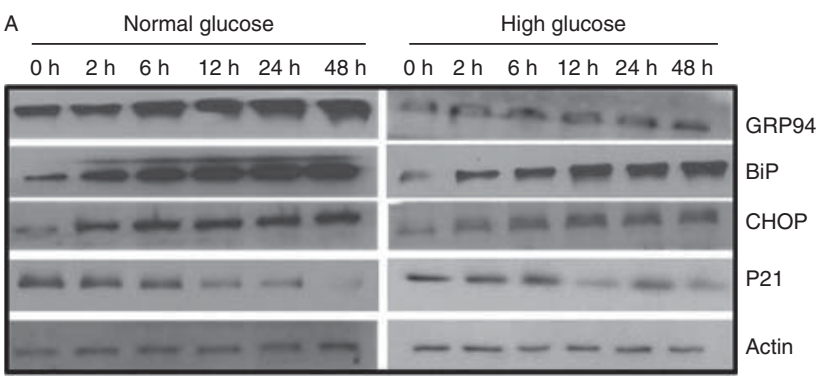

B

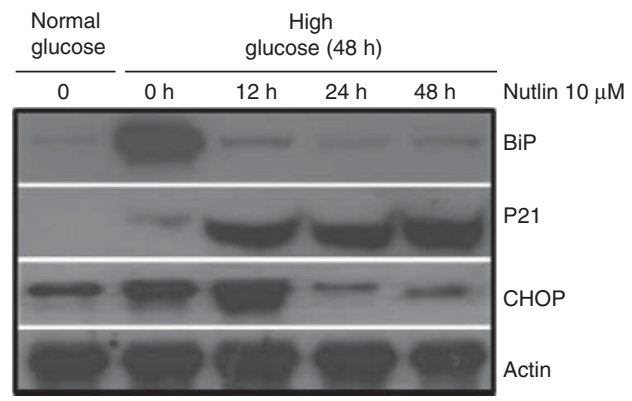

Figure 1

Regulation of P21 expression during ER stress in pancreatic $\beta$-cells. (A) Western blot analysis for GRP94, BiP, CHOP, and P21 in HIT-T15 (Syrian hamster islet cells) cultured in glucose-deprived or high-glucose media ( $25 \mathrm{mM}$ ) for the indicated periods. Both high and low levels of glucose induced the expression of the glucose-regulated proteins (GRPs), major ER stress-inducible chaperones BiP and GRP94, and induced the pro-apoptotic factor CHOP and the concomitant suppression of P21. (B) Effects of nutlin$3 a(\mathrm{Nu}, 10 \mu \mathrm{M})$, added in high-glucose media, on P21, CHOP, and BiP expression levels. In this experiment, HIT-T15 cells were cultured for $48 \mathrm{~h}$ in media containing $25 \mathrm{mM}$ glucose and supplemented with $\mathrm{Nu}$ for the indicated times before protein extraction.

BiP during the UPR (Fig. 1A). Furthermore, we noted that $\mathrm{Nu}$ activates P21 expression by a P53-dependent mechanism (el-Deiry et al. 1993, Vassilev et al. 2004) that effectively relieved cells from ER stress, as evidenced by the inhibition of $\mathrm{BiP}$ and $\mathrm{CHOP}$ expression during $\mathrm{Nu}$ treatment of cells cultured in high-glucose media (Fig. 1B).

Similar effects were observed in primary pancreatic islets subjected to glucose deprivation or glucotoxicity. However, as soon as primary islets are adapted to in vitro culture P21 is transiently upregulated, which may exaggerate the subsequent reduction in P21 expression (not shown).

\section{Transcriptional regulation of P21 during ER stress}

The concomitant suppression of P21 and stimulation of CHOP, BiP, and GRP94 in HIT-T15 cells under culture conditions with aberrant glucose levels prompted us to propose the hypothesis that P21 is regulated during UPR at the level of transcription. To test this hypothesis, a luciferase-based reporter construct incorporating the P21 promoter was generated and tested for its activity in HIT-T15 cells exposed for $16 \mathrm{~h}$ to increasing amounts of Tun. As shown in Fig. 2A, a transient increase in the levels of P21 promoter activity was initially observed when Tun was added at a dose of $0.1 \mu \mathrm{g} / \mathrm{ml}$, followed by a progressive dosedependent inhibition at higher concentrations, and became maximal when Tun was added at $5 \mu \mathrm{g} / \mathrm{ml}$. Under these conditions, a moderate stimulation of CHOP expression was recorded at concentrations between 0.1 and $1 \mu \mathrm{g} / \mathrm{ml}$ that became maximal at higher concentrations of $2-5 \mu \mathrm{g} / \mathrm{ml}$ (Fig. 2B). These observations indicate that moderate induction of ER stress stimulates- whereas intense ER stress suppresses P21 expression at the level of transcription.

\section{CHOP competes with C/EBPa to regulate $P 21$ transcription}

The transcription factor CHOP is regulated by ER stress and its expression is linked to the induction of the proapoptotic program of the UPR (Ron \& Habener 1992, Marciniak et al. 2004). Thus, CHOP appears to be a good candidate for contributing to the transcriptional regulation of P21 during ER stress. Exogenous CHOP expression that inhibited the activity of the $P 21$ promoter in HIT-T15 cells is indicted in Fig. 2C. Furthermore, as the inhibitory effect of CHOP on gene transcription is at least in part due to competition with $\mathrm{C} / \mathrm{EBP}$ family members for promoter binding (Ron \& Habener 1992, Marciniak et al. 2004), it is conceivable that the latter stimulate P21 transcription by binding to CCAAT regulatory elements and are displaced by CHOP during ER stress. Indeed, both $\mathrm{C} / \mathrm{EBPa}$ and $\mathrm{C} / \mathrm{EBPb}$ have been previously reported to stimulate the transcription of P21 (Timchenko et al. 1996, Chinery et al. 1997, Cram et al. 1998). In a result consistent with this notion, increasing amounts of CHOP dosedependently inhibited C/EBPa-induced stimulation of luciferase activity in HIT-T15 cells (Fig. 2C, lower panel), while increasing amounts of $\mathrm{C} / \mathrm{EBPa}$ abrogated the inhibitory effects of CHOP (Fig. 2C, upper panel).

\section{P21 regulates the severity of glucotoxicity in vitro}

P21 produces strong pro-survival activity that has been studied primarily in the context of carcinogenesis and chemotherapeutic drug efficacy. In order to test whether these protective effects of P21 are also produced during glucotoxicity, pancreatic islets were isolated from WT and P21-deficient mice (Brugarolas et al. 1995) and their survival was assessed after culturing them in media containing increased amounts of glucose. While no gross morphological differences were noted between WT and

Published by Bioscientifica Ltd. 
A

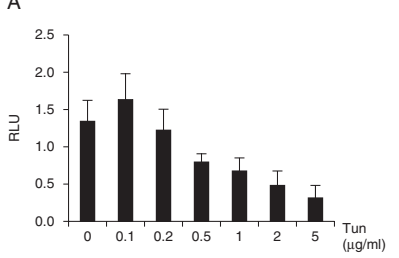

B

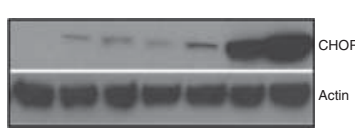

C
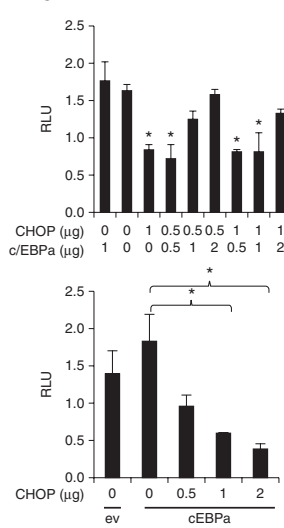
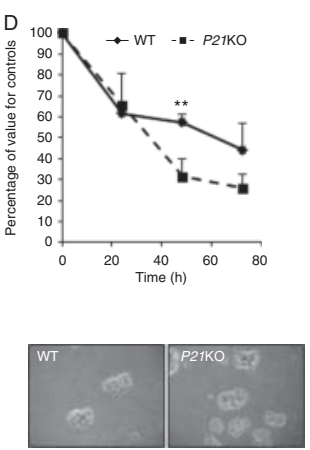
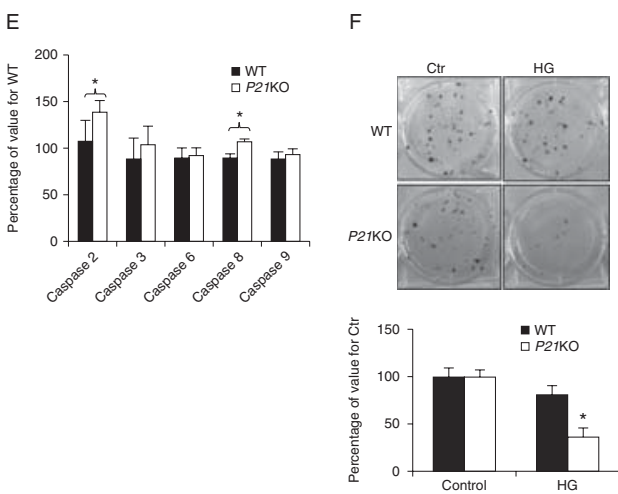

Figure 2

P21 expression is regulated by CHOP at the level of transcription and determines survival of cells during ER stress. (A) Luciferase activity expressed in relative luciferase units (RLU) of the L1R1 reporter construct in HIT-T15 insulinoma cells cultured for $16 \mathrm{~h}$ with tunicamycin at the concentrations indicated. This experiment was carried out at least three times in triplicates and the results of a single experiment expressed as average values \pm S.E.M. are shown. (B) Protein extracts for the experiment described in (A) from the three triplicates pooled together were subjected to immunoblot analysis for CHOP. Actin levels were assessed as a loading control. (C) Competition between $\mathrm{CHOP}$ and C/EBPa in the regulation of $\mathrm{P} 21$ promoter. The effects of increasing amounts of C/EBPa (upper panel) and CHOP (lower panel) on luciferase activity for a construct incorporating the L1R1 fragment of $P 21$ promoter are shown. In the upper panel, two concentrations of CHOP were used $(0.5$ and $1 \mu \mathrm{g})$. The experiment was carried out using HIT-T15 insulinoma cells and the results were normalized by performing co-transfection with a plasmid constitutively expressing Renilla luciferase. The data shown are representative of three independent experiments. Each experiment was performed in triplicates and error bars represent \pm s.D. * $P<0.05$ vs mock-transfected cells (Student's $t$-test). (D) Viability, expressed as percentages of the value for controls, of pancreatic islets isolated from WT and $P 21 \mathrm{KO}$ mice that were cultured in media containing high levels of glucose $(25 \mathrm{mM})$ for the indicated time periods. Representative microphotographs of WT and $P 21 \mathrm{KO}$ islets are shown in the lower panel. Error bars indicate S.D. ${ }^{* * P}<0.05$ versus mock-transfected cells (paired Student's $t$-test). (E) Diagrammatic presentation of caspases 2, 3, 6, 8, and 9 activation in $P 21 \mathrm{KO}$ islets, following culture in high-glucose media. Values are expressed as percentages of the activation in islets from WT mice. ${ }^{*} P<0.05$ versus WT (paired Student's $t$-test). (F) Clonogenic survival of WT and P21KO MEFs cultured in high glucose (HG) media ( $24 \mathrm{~h}$ ). Representative petri dishes are shown in combination with the genotype and the exposure conditions that are indicated in the margins (upper panel). Average values for three independent experiments are shown in the graph (lower panel) expressed as percentages of the values for controls (Ctr, regular media). Error bars indicate S.D. ${ }^{*} P<0.05$ versus controls (paired Student's $t$-test).

\section{P21 protects from diet-induced type 2 diabetes}

cantly reduced cell viability as compared with their WT counterparts when cultured in media containing high levels of glucose (Fig. 2D). It is noteworthy that despite the increased sensitivity of $P 21 \mathrm{KO}$ islets to glucotoxicity, their isolation was more efficient than that of the controls (results not shown), probably because P21-regulated cell cycle arrest has been compromised in the P21-deficient islets permitting bypass of the cell-cycle checkpoints that occur during growth of primary cells in culture. Consistent with their reduced viability, an overall increase in caspase activation was noted for several caspases in P21KO islets following culture in high-glucose media, with the differences in activation for caspases 2 and 8 reaching statistical significance compared with activation in WT controls $(P<0.05$; Fig. 2E). Similar observations were also made when the clonogenic efficiency of WT and P21KO primary mouse embryonic fibroblasts (MEFs) was evaluated in high-glucose media: P21KO fibroblasts exhibited significantly reduced clonogenic activity, less than $50 \%$ of the activity of controls (Fig. 2F).
In view of the anti-apoptotic activity of P21 in the context of tumorigenesis and our observations regarding its protective effect against glucotoxicity in HIT-T15 cells and pancreatic islets, the reduction in P21 expression during the most advanced stages of ER stress indicates that ablation of P21 may modulate the manifestation of pathologies associated with ER stress. Such condition is exemplified by type 2 diabetes (T2D) in which pancreatic $\beta$-cell death is induced by ER stress augmenting pancreatic dysfunction (Papa 2012). In order to test this hypothesis, P21-deficient mice (Brugarolas et al. 1995) and WT controls were fed with HFD/sucrose-sweetened drinking water, and blood glucose levels were monitored. This diet mimics the conditions that cause obesity and predisposition to $\mathrm{T} 2 \mathrm{D}$ in humans by mechanisms engaging induction of ER stress (Kahn et al. 2006, Scheuner \& Kaufman 2008, Islam \& Loots 2009, Papa 2012). As shown in Fig. 3A, ablation of P21 rendered mice more sensitive to experimental diabetes as evidenced by the elevated blood

Published by Bioscientifica Ltd. 

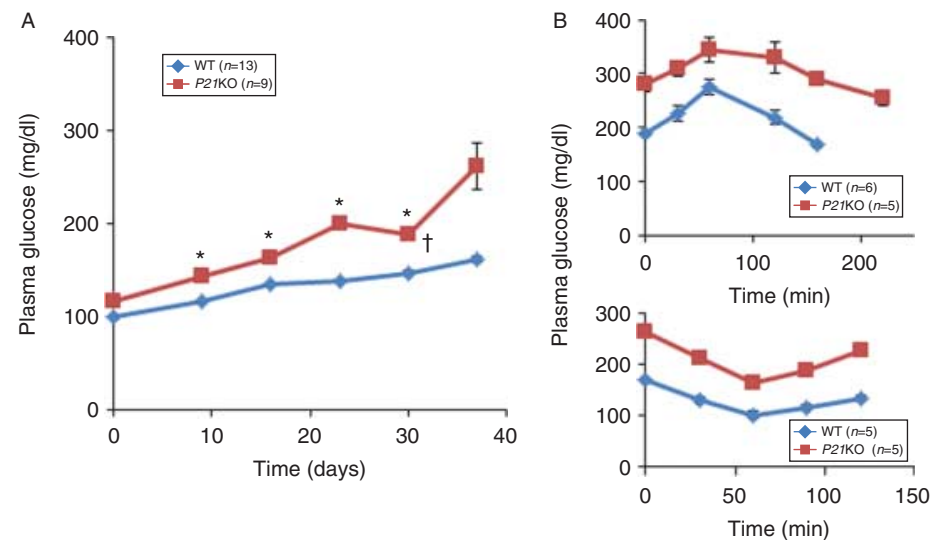
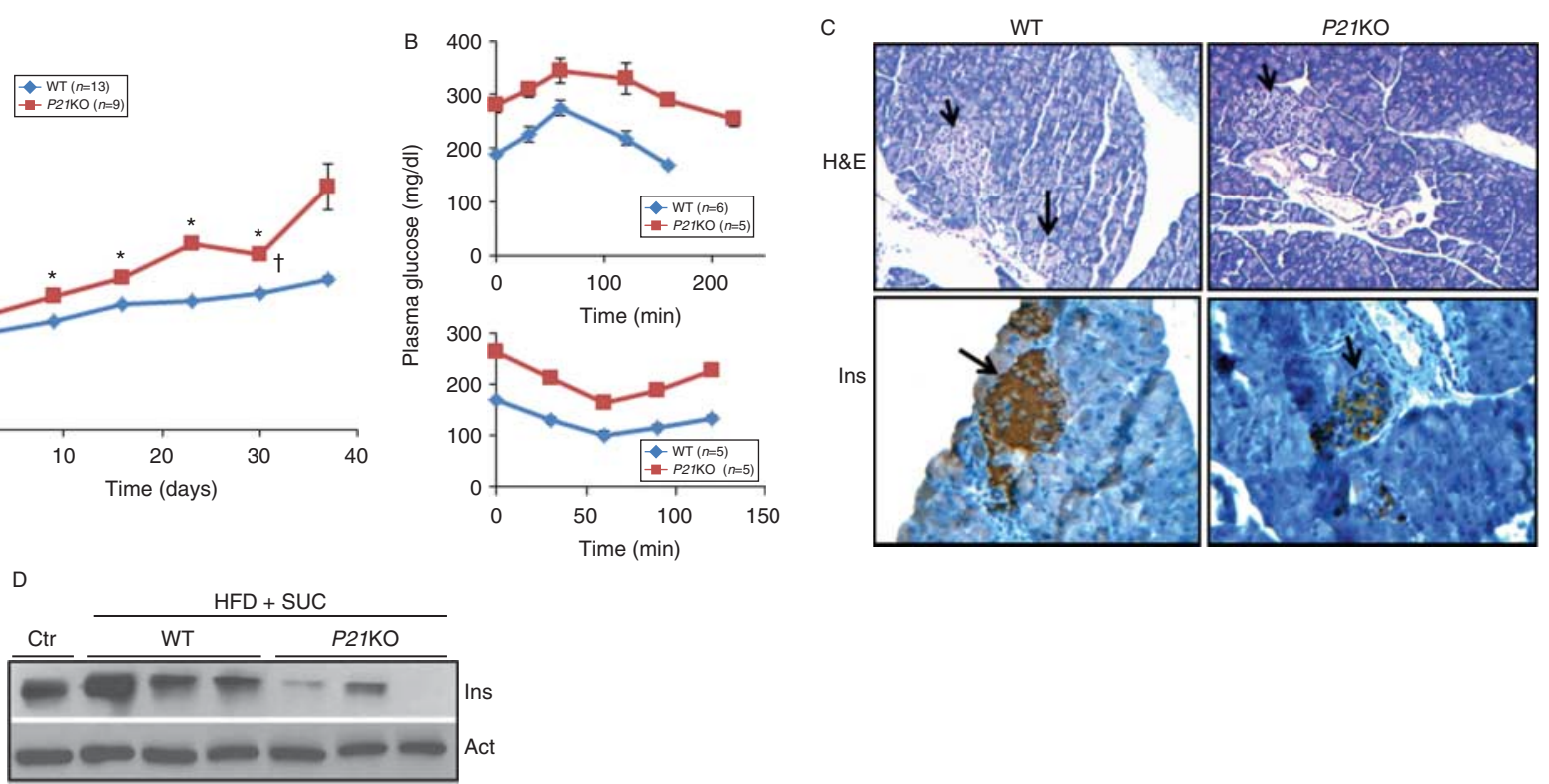

Figure 3

P21 protects against T2D. (A) T2D was induced by administration of HFD ( $40 \%$ calories/fat) and sucrose ( $10 \%$ constantly in drinking water) in 4-week-old mice and plasma glucose levels were monitored. One animal from the $P 21 \mathrm{KO}$ group died during the experiment and is indicated by a dagger (top left). ${ }^{*} P<0.05$. (B) Glucose tolerance (top) and insulin resistance (bottom) tests were performed using WT and $P 21 \mathrm{KO}$ mice following T2D induction, 30 days after initiation of administration of the special diets, as described in 'Materials and methods' section. (C) Histology and insulin expression in pancreata from WT and P21KO animals following induction of T2D. Histological, pancreatic morphology is not markedly different between WT and P21KO mice following T2D induction (upper panel); however, insulin production has been compromised as indicated by immunohistochemistry (lower panel, brown precipitant). Arrows indicate islets. Upper panel: $10 \times$ magnification and lower panel: $20 \times$ magnification. (D) Western blot analysis for pro-insulin in pancreas tissues of WT and $P 21 \mathrm{KO}$ mice ( $n=3 \mathrm{mice} / \mathrm{group}$ are shown) following induction of diabetes. Insulin expression in WT mice receiving a normal diet is also shown (Ctr). Actin was used as a protein loading control. glucose levels recorded. Furthermore, P21-deficient mice exhibited a delayed response in glucose homeostasis as indicated by the results of glucose tolerance tests (Fig. 3B, top panel). Moderate insulin sensitivity was retained in the $P 21$ KO mice, but glucose levels did not reach normal levels, as opposed to the WT mice, which showed transient increases in glucose levels after administration of insulin (Fig. 3B, lower panel). Thus, P21 ablation renders animals more sensitive to diet-induced diabetes. Consistent with the compromised glucose homeostasis were the insulin levels in the pancreatic islets, which were decreased in the P21-deficient mice as compared with the controls following induction of experimental T2D (Fig. 3C and D).

\section{$\mathrm{Nu}$ is beneficial for the management of experimental diabetes in mice}

As P21 ablation increase sensitivity to diabetes, we proposed the hypothesis that pharmacological stimulation of P21 expression may be beneficial during disease development as it could restore $\beta$-cell survival, insulin production, and pancreatic function. In order to test this hypothesis, we utilized $\mathrm{Nu}$, a small-molecule inhibitor of P53-MDM2 interaction that stimulates P21 expression, to treat diabetic mice. As shown in Fig. 4A, Nu acutely stimulated P21 expression in vivo at levels similar to those for DOX, a standard stimulator of P21 expression that operates by P53-dependent mechanisms. After administration of $\mathrm{Nu}$ in diabetic mice, P21 levels also increased, validating the P21-induced activity of $\mathrm{Nu}$ in the context of diabetes (Fig. 4B). As shown in Fig. 4C, D and E, administration of $\mathrm{Nu}$ effectively restored glucose homeostasis and improved pancreatic morphology, indicating that stimulation of P21 expression is beneficial for the management of diabetes. Importantly, only P21-positive mice, but not P21-deficient mice, were sensitive to the therapeutic effects of $\mathrm{Nu}$, ruling out the possibility that this anti-diabetic activity of $\mathrm{Nu}$ represents a P21-independent effect of P53 (Fig. 4C, D and E). Measurement of fasting insulin in the serum of HFD-sucrose fed animals indicated a progressive increase in baseline insulin levels in both WT and P21KO mice, with values for the WT being almost 1.5-fold those of the $P 21 \mathrm{KO}(336 \pm 11 \mathrm{vs} 217 \pm 11 \mathrm{pg} / \mathrm{ml})$, and for plasma glucose were in the range of around $200 \mathrm{mg} / \mathrm{dl}$ for both (Fig. 4C).

Published by Bioscientifica Ltd. 

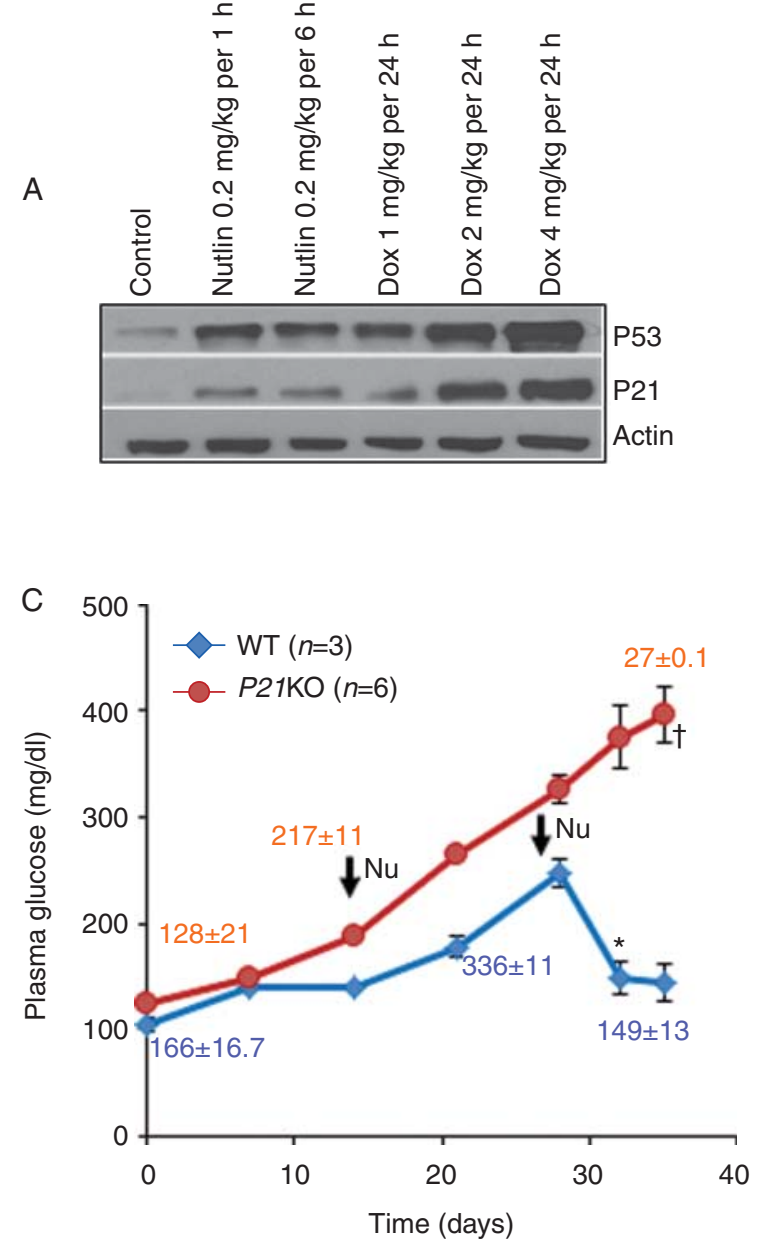

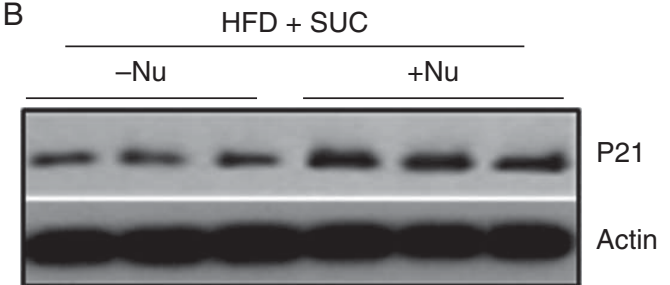

D

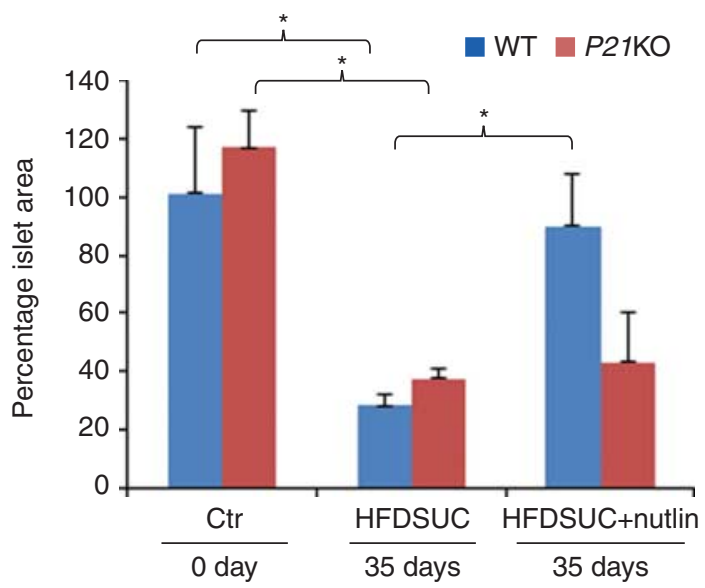

$E$
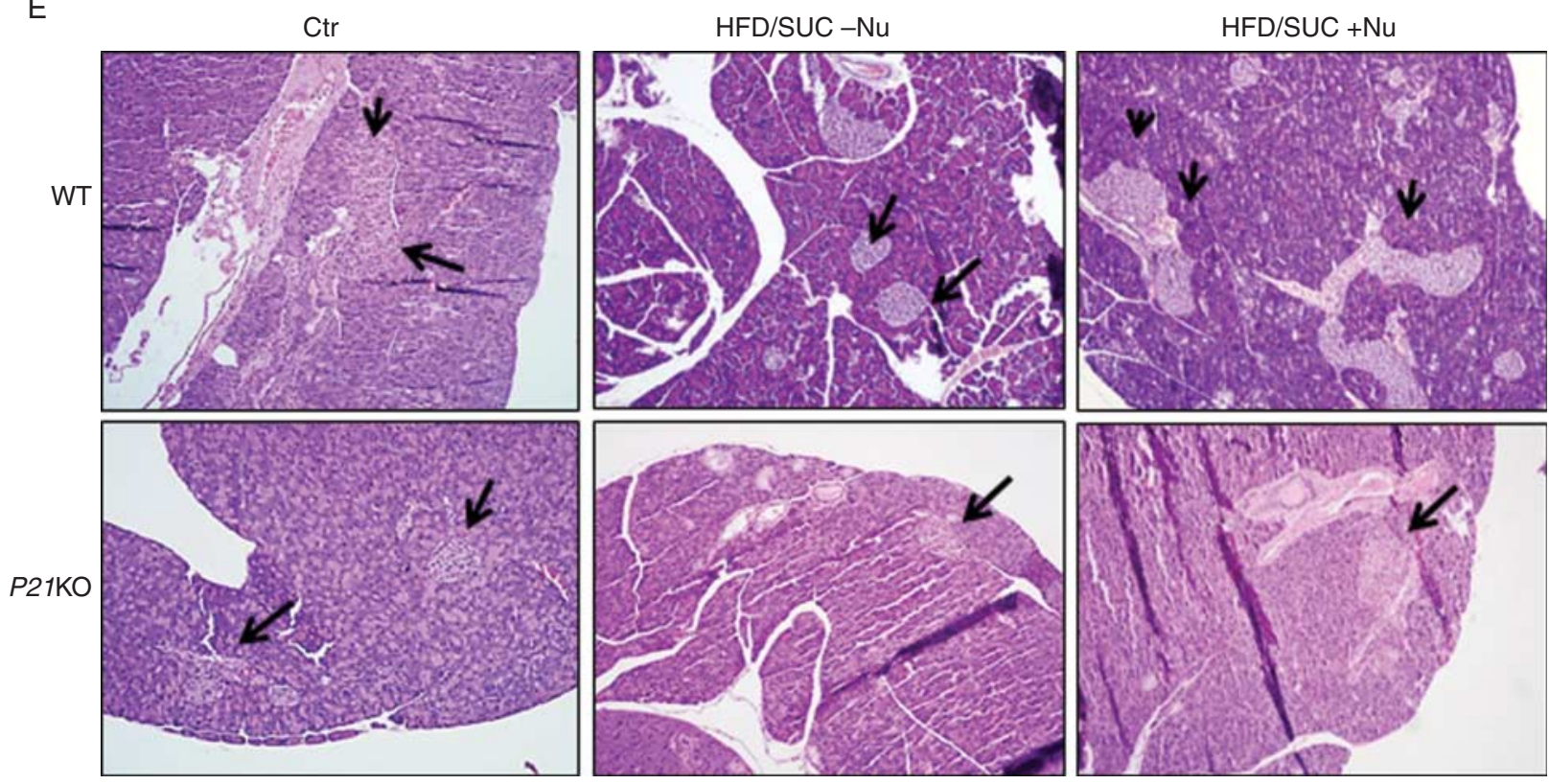
In the P21KO mice, despite the Nu treatment, plasma insulin decreased considerably after continuous administration of the HFD-sucrose regime, but only moderately decreased in the WT mice (Fig. 4C).

Subsequently, we investigated whether this protective activity of $\mathrm{Nu}$ is also operative in another model of diabetes, specifically that induced by the administration of STZ followed by HFD. In this model of experimental diabetes, a considerable fraction of the pancreatic $\beta$-cells is damaged by the STZ-increased load of insulin production to the remaining surviving islets, ultimately causing ER stress, pancreatic dysfunction, and development of diabetes. In these animals, initially an increase in the levels of plasma insulin is observed for as long as the islets maintain their capacity to produce insulin, that is followed by a progressive decrease when their insulin-producing capacity is abolished (Fig. 5A). A group of the animals that received STZ/HFD, after induction of diabetes had been confirmed by glucose measurements on fasted animals, received $\mathrm{Nu}$, which stimulated the levels of P21 in the pancreas (Fig. 5B). As shown in Fig. 5A, daily administration of $\mathrm{Nu}$ was sufficient to restore pancreatic function and insulin production and to reduce the plasma glucose levels in the diabetic mice. The results of glucose tolerance tests on these animals indicated that $\mathrm{Nu}$ treatment had restored glucose regulation (Fig. 5C). Histological analyses of the pancreata of the experimental animals indicated that diabetic mice that received vehicle exhibited reduced numbers of largely hypoplastic islets and animals that had been treated with $\mathrm{Nu}$ displayed a higher number of islets that were frequently hyperplastic (Fig. 5D and E). Furthermore, insulin expression in islets (Fig. 5D and F) and serum insulin levels (Fig. 5A) were compromised in the controls as compared with the nutlinreceiving animals. Results presented in Figure 5G, are indicative of moderate suppression of P21 levels and the induction of ER stress-associated chaperones CHOP and $\mathrm{BiP}$ in the pancreata of both models of diabetic animals.

\section{Discussion}

Understanding how UPR progresses from the adaptive mode toward the pro-apoptotic mode of action may have important implications for understanding the development of various pathologies, including diabetes. In this study, we have shown that during ER stress, P21 is regulated by the transcription factor CHOP. According to our findings, P21 promotes the adaptive function of the UPR, while its suppression by $\mathrm{CHOP}$ appears to be permissive of the execution of its pro-apoptotic activity. In order to exclude the direct contribution of P53 to P21 regulation, we utilized a promoter fragment that did not contain the P53 consensus binding site. Thus, the recorded P21 suppression appears to be independent of P53 because the P53 binding site was not included in the promoter constructs utilized. At least in part, the inhibitory activity of CHOP on P21 during advanced ER stress may operate by competition with members of the C/EBP family of transcription factors. Not surprisingly, during mild ER stress at low doses of Tun, $P 21$ promoter activity was modestly stimulated. This is consistent with the direct, stimulatory effects of $\mathrm{CHOP}$ on gene transcription (Ubeda et al. 1996). In the pancreata of STZ-HFD and especially of HFD-sucrose diabetic mice, P21 levels were also suppressed (Fig. 5G). Considering that islets represent only a fraction of the pancreatic cells, a more widespread inhibition of P21 expression in various pancreatic cell populations is likely.

The effect of ER stress on the expression of P21 is not $\beta$-cell-specific, but rather global, as it operates in various cell types and may represent a promising chemosensitizing strategy for cancer management (Mihaildou, et al. 2015). Recently, inhibition of P21 by P53/47 during ER stress has also been discovered and proposed for lowering the apoptotic threshold of cells to genotoxic drugs. Consistent with these findings, earlier observations involving WT and P53-deficient mice and cells revealed a remarkable sensitivity to ER-stress-inducing stimuli in the

\section{Figure 4}

Nutlin-3a (Nu) is beneficial in HFD/sucrose-induced diabetes in mice. (A) P53 and $P 21$ expression in pancreas of WT mice following the administration of $\mathrm{Nu}$ and DOX by i.p. injection at the indicated doses. Treatment periods are indicated. Actin was used as a loading control. (B) P21 expression in the pancreas of diabetic mice (HFD and sucrose constantly in drinking water) that received nutlin or vehicle. Actin was used as a loading control. (C) Administration of Nu restores glucose homeostasis in WT, but not in P21KO mice. In this experiment WT and P21KO mice were administered HFD/sucrose as described and as soon as blood glucose levels exceeded $180 \mathrm{mg} / \mathrm{dl}$ they received $\mathrm{Nu}$ (five i.p. daily injections at $4 \mathrm{mg} / \mathrm{kg}$ ) and blood glucose levels were monitored. The dagger indicates the time point at which four out of six $P 21 \mathrm{KO}$ mice died during the course of this experiment. Fasting insulin serum measurements are shown in $\mathrm{pg} / \mathrm{ml}$ for the $P 21 \mathrm{KO}$ (red) and WT (blue) animals. Average values \pm S.E.M. are shown. ${ }^{*} P<0.05$ (Student's $t$-test).

(D) Diagrammatic presentation of the percentage islet area in the pancreas of WT (blue) and P21KO (red) control (Ctr, nondiabetic), diet-induced diabetic (HFDSUC), and HFDSUC mice receiving nutlin. Average values expressed as percentage islet area relative to that for controls \pm S.E.M. are shown. ${ }^{\star} P<0.05$ (Student's t-test). (E) Histology of pancreata from WT and $P 21 \mathrm{KO}$ animals following induction of T2D and after Nu therapy. Nu treatment considerably improves pancreatic morphology in the WT mice as evidenced by the increase in the abundance of islets (arrows). Magnification: $10 \times$.

Published by Bioscientifica Ltd. 
A

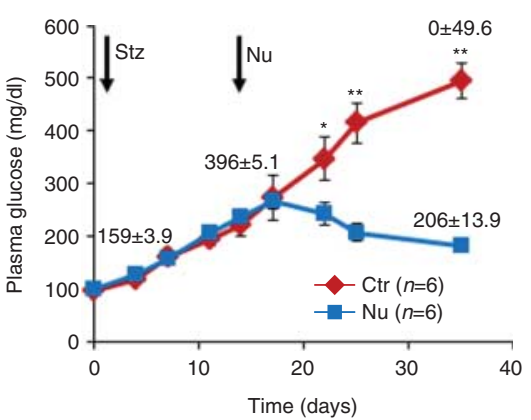

B

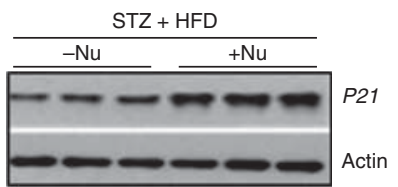

C

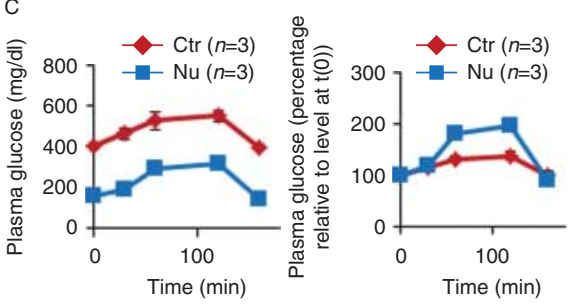

$\mathrm{D}$

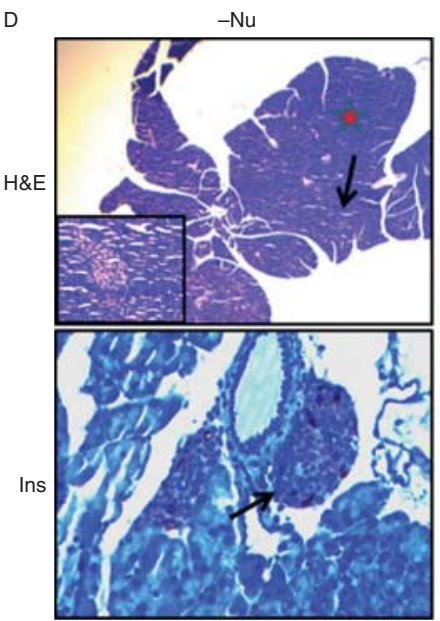

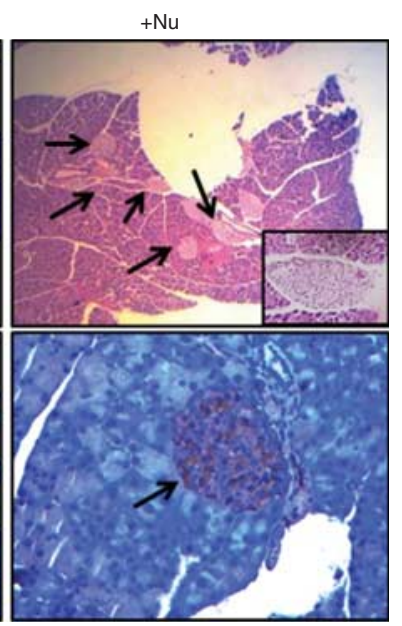

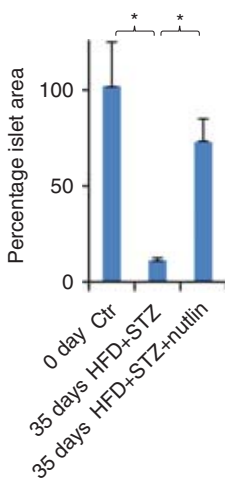

$\mathrm{F}$

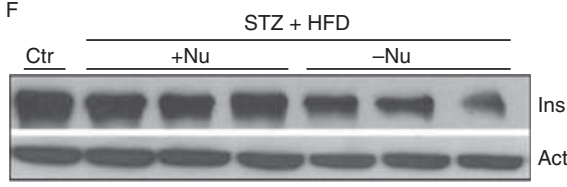

G Control STZ + HFD HFD $\frac{\text { Diabetic }}{\text { Siabetic }}$

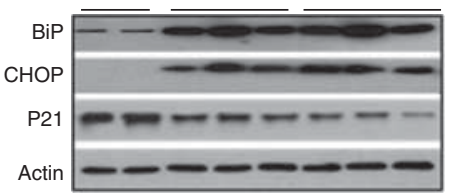

Figure 5

Nutlin-3a (Nu) is beneficial in STZ/HFD-induced diabetes in mice. (A) Plasma glucose levels ( $n=6$ mice/group) after $5 \mathrm{~h}$ fasting of diabetic mice following administration of nutlin (blue) or saline (red). Nu was administered by five i.p. daily injections at $4 \mathrm{mg} / \mathrm{kg}$. Streptozotocin (STZ) was administered at $50 \mathrm{mg} / \mathrm{kg}$ daily for 5 consecutive days i.p. in 4 -week-old animals. The time points at which STZ and Nu administration were initiated are indicated by arrows. Fasting insulin serum measurements are shown in $\mathrm{pg} / \mathrm{ml}$, above each graph at the corresponding time points. Average values \pm s.D. are shown. ${ }^{*} P<0.05$ and $* * P<0.01$ (Student's $t$-test). (B) P21 expression in the pancreata of diabetic mice (HFD + SUC) that received nutlin or vehicle. Actin was used as a loading control. (C) Results of glucose tolerance tests performed at the end of the experiment (values from three individual mice per group are shown) expressed as absolute glucose measurements (left) or percentages of values at $t=0$ for each group (right). Glucose tolerance tests were performed by administering i.p. glucose at $2 \mathrm{mg} / \mathrm{g} \mathrm{BW}$. HFD and control diets contained 40 and $10 \%$ calories as fat respectively. (D) Histology of pancreata from diabetic mice. Islets of Langerhans (shown in insets and pointed by arrows in outsets) are sparse and hypotrophic in the vehicletreated animals (left panel) while those in the Nu-treated mice are abundant and hyperplastic (right panel). Histologically, the eosinophilic staining of the cytoplasm in the Nu-treated animals is consistent with the intense protein synthesis activity (zymogen granule production) of the exocrine pancreas (red asterisk). Upper panels ( $4 \times$ magnification) show H\&E stained sections while the lower panels show ( $20 \times$ magnification) immunostaining for insulin (brown chromogen). (E) Diagrammatic presentation of the percentage islet area in the pancreata of control (Ctr, nondiabetic), diabetic (HFD + STZ), and diabetic mice receiving nutlin. The analysis was performed on nondiabetic controls and diabetic treated and untreated mice at the termination of the experiment. Average values \pm s.E.M. are shown. ${ }^{\star} P<0.05$ (Student's $t$-test). (F) Western blot analysis of proinsulin from the pancreata of WT diabetic mice treated $(+\mathrm{Nu})$ or not $(-\mathrm{Nu})$ with $\mathrm{Nu}$. Actin was used as a protein loading control. (G) Western blot analysis for BiP, CHOP, and P21 in the pancreata of diabetic (STZ+ HFD and HFD + SUC) and control mice. Actin was used as a loading control. absence of P53 (Dioufa et al. 2012). Furthermore, ER-stressrelated pro-apoptotic activity may contribute to the increased sensitivity of P53-deficient cells to DNAdemethylating agents (Leonova et al. 2013). The fact that nutlin was able to blunt the induction of ER stress induced by high levels of glucose indicates that P53/P21 activity may not only be targeted by- but also operate as a regulator of ER stress.

In the context of $\beta$-cell physiology, this ER-stressrelated suppression of P21 was observed during culture of $\beta$-cells and islets under high- or low-glucose conditions. Albeit operating by different mechanisms, both glucose deprivation and high levels of glucose induce ER stress. The first by interfering with protein glycosylation; while the second by triggering overstimulation of the secretory pathway for insulin production. This inhibition of P21 expression facilitates ER-stress-associated death as indicated by the reduced survival and increased caspase activation of the islets that had been isolated from P21deficient animals during culture in media containing high

Published by Bioscientifica Ltd. 


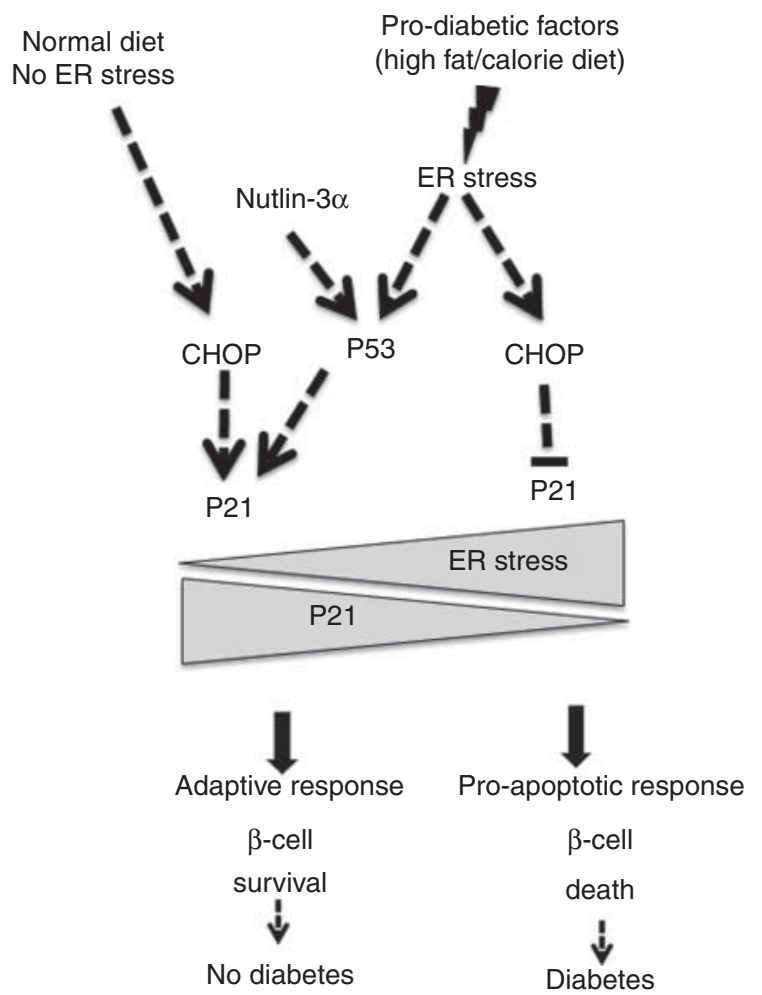

\section{Figure 6}

Diagrammatic depiction of the protective role of P21 in diabetes. Prodiabetic factors such as high-fat and high-calorie diet induce ER stress that suppresses P21 by mechanisms that involve CHOP. This CHOPdependent suppression of $\mathrm{P} 21$ ultimately compromises pancreatic function and facilitates the development of diabetes. Pharmacological stimulation of P21 with nutlin-3a facilitates $\beta$-cell survival and pancreatic function and is beneficial for the management of diabetes. The presumed $\mathrm{CHOP}_{\text {- }}$ independent stimulation of P21 expression during ER stress, that may be P53-dependent, is also indicated.

levels of glucose. Notably, although increased activity was detected in all five caspases evaluated in P21-deficient islets as compared with control islets, statistically significant differences were observed only for caspases 2 and 8, probably implying specificity of the anti-apoptotic activity of P21. In particular, caspase 2 has been identified previously as a target of P21 (Baptiste-Okoh et al. 2008). Furthermore, a specific role for caspase 8 in the regulation of $\beta$-cell mass and insulin secretion, both of which are affected by P21 in the experimental models described in this study, has been proposed (Liadis et al. 2007). Similar pro-survival activity was observed in fibroblasts as well, notwithstanding that protection from oxidative stress and mitochondrial dysfunction may represent the underlying mechanism in the fibroblasts (Russell et al. 2002).

The protective activity against glucotoxicity of P21 on $\beta$-cells and islets prompted us to further explore our findings in the context of diabetes, in at which ER stress-associated death facilitates pancreatic dysfunction and disease pathogenesis. The latter is clearly illustrated by the resistance of Chop-deficient mice to experimental diabetes, which is due to decreased $\beta$-cell death (Oyadomari et al. 2002). The role of P21 in promoting the adaptive activity of the UPR was initially manifested in the increased sensitivity of the P21-deficient mice to diet-induced diabetes, as compared with the WT controls (Fig. 3). When fed a regular diet and without the induction of diabetes, P21-null mice exhibit no evidence of diabetes and display a metabolic profile that is indistinguishable from that of their WT counterparts, confirming earlier observations (Cozar-Castellano et al. 2006). It is noteworthy though that in this study a trend, albeit insignificant, towards reduced islet numbers in the older P21-deficient animals was recorded (Secchiero et al. 2013). Consistent with this notion, the baseline insulin levels were moderately reduced in the $P 21 \mathrm{KO}$ mice as compared with their WT counterparts (Fig. 4C).

After prolonged administration of a diabetes-inducing diet, that causes ER stress and eventually promotes pancreatic dysfunction, P21 deficiency facilitates $\beta$-cell loss and the onset of diabetes. This role of P21 in modulating the outcome of the UPR is also exemplified by the observation that stimulation of P21 expression by $\mathrm{Nu}$, a small-molecule activator of P53 that stimulates P21 expression, appears beneficial for the management of diabetes, as indicated by the restoration of pancreatic function in diabetic mice that have received $\mathrm{Nu}$. In this model of diabetes, insulin levels initially increase and subsequently decrease, probably marking the progression of diabetes from being an insulin-dependent to an insulinindependent disease (Fig. 4C). Nu treatment of the WT animals, but not the P21-deficient animals, restored insulin levels, reflecting the presence of functional islets in the WT but not the P21KO mice. Also consistent with the restoration of pancreatic function was the increase in the area of pancreas occupied by islets following $\mathrm{Nu}$ administration in the WT but not the P21-deficient animals (Fig. 4D). This resistance of P21-deficient animals to the therapeutic activity of $\mathrm{Nu}$ rules out the possibility of this reflecting activity that is P53-dependent but P21independent. Similar protective activity was also revealed in another model of diabetes, induced by STZ combined with HFD. $\mathrm{Nu}$ administration restored islet area in the pancreas, as well as blood glucose and insulin levels.

Our findings, albeit by a different mechanism, are consistent with recent results, indicating that $\mathrm{Nu}$ treatment concomitant with STZ administration inhibits diabetes (Secchiero et al. 2013). Furthermore, conditional

Published by Bioscientifica Ltd. 
expression of P21 in the islet cells of transgenic mice causes increased pancreatic cell regeneration following STZ administration (Yang et al. 2009).

While in this study, we focused on the role of P21 in $\beta$-cell survival, additional in addition mechanisms through which P21 interferes with glucose homeostasis may also operate. Indeed, P21 may directly regulate insulin expression, as indicated by the increased anti-insulin immunoreactivity in the islets of mice that received nutlin. Furthermore, marginally reduced levels of plasma insulin were measured in P21-deficient animals - both diabetic and control, despite that the overall area of islets in the pancreas was modestly increased in these animals. Thus, the role of P21 during diabetes may not be limited to the regulation of $\beta$-cell survival.

Collectively, we identified P21 as a target of CHOP transcription factor (Fig. 6). Our results indicate that, in the context of diabetes, the expression of P21 inhibits pancreatic dysfunction and that interference with P21 activity during ER stress may be beneficial in diabetes and other conditions in which modulation of sensitivity of cells to ER-stress-associated apoptosis is desired.

\section{Declaration of interest}

The authors declare that there is no conflict of interest that could be perceived as prejudicing the impartiality of the research reported.

\section{Funding}

C Mihailidou has been supported by a Fellowship that is co-financed by the European Union (European Social Fund (ESF)) and Greek National funds through the Operational Program 'Education and Lifelong Learning' of the National Strategic Reference Framework (NSRF) - Research Funding Program: Heracleitus II. This study was supported by a grant from the Empirikion Foundation and EXCELLENCE-2011 (ARISTEIA) Grant (11EXC311), funded by the European Social Fund-European Union and National Resources.

\section{Author contribution statement}

C Mihailidou designed and performed experiments, analyzed results, and wrote the manuscript; I Chatzistamou performed histological analysis, designed experiments, analyzed results, and wrote the manuscript; A G Papavassiliou designed experiments, analyzed results, and wrote the manuscript; $\mathrm{H}$ Kiaris designed and performed experiments, analyzed results, and wrote the manuscript.

\section{References}

Back SH \& Kaufman RJ 2012 Endoplasmic reticulum stress and type 2 diabetes. Annual Review of Biochemistry 81 767-793. (doi:10.1146/ annurev-biochem-072909-095555)
Baptiste-Okoh N, Barsotti AM \& Prives C 2008 Caspase 2 is both required for p53-mediated apoptosis and downregulated by p53 in a p21dependent manner. Cell Cycle 7 1133-1138. (doi:10.4161/cc.7.9.5805)

Blagosklonny MV 2002 Are p27 and p21 cytoplasmic oncoproteins? Cell Cycle 1 391-393. (doi:10.4161/cc.1.6.262)

Brugarolas J, Chandrasekaran C, Gordon JI, Beach D, Jacks T \& Hannon GJ 1995 Radiation-induced cell cycle arrest compromised by p21 deficiency. Nature 377 552-557. (doi:10.1038/377552a0)

Chinery R, Brockman JA, Peeler MO, Shyr Y, Beauchamp RD \& Coffey RJ 1997 Antioxidants enhance the cytotoxicity of chemotherapeutic agents in colorectal cancer: a p53-independent induction of p21 ${ }^{\mathrm{WAF} 1 / \mathrm{CIP} 1}$ via C/EBP $\beta$. Nature Medicine 3 1233-1241. (doi:10.1038/ nm1197-1233)

Cozar-Castellano I, Haught M \& Stewart AF 2006 The cell cycle inhibitory protein $\mathrm{p} 21^{\mathrm{cip}}$ is not essential for maintaining $\beta$-cell cycle arrest or $\beta$-cell function in vivo. Diabetes 55 3271-3278. (doi:10.2337/db06-0627)

Cram EJ, Ramos RA, Wang EC, Cha HH, Nishio Y \& Firestone GL 1998 Role of the CCAAT/enhancer binding protein- $\alpha$ transcription factor in the glucocorticoid stimulation of $\mathrm{p} 21^{\text {waf1/cip } 1}$ gene promoter activity in growth-arrested rat hepatoma cells. Journal of Biological Chemistry $\mathbf{2 7 3}$ 2008-2014. (doi:10.1074/jbc.273.4.2008)

el-Deiry WS, Tokino T, Velculescu VE, Levy DB, Parsons R, Trent JM, Lin D, Mercer WE, Kinzler KW \& Vogelstein B 1993 WAF1, a potential mediator of p53 tumor suppression. Cell 75 817-825. (doi:10.1016/ 0092-8674(93)90500-P)

Dioufa N, Chatzistamou I, Farmaki E, Papavassiliou AG \& Kiaris H 2012 p53 antagonizes the unfolded protein response and inhibits ground glass hepatocyte development during endoplasmic reticulum stress. Experimental Biology and Medicine 23 1173-1180. (doi:10.1258/ebm. 2012.012140)

Fonseca SG, Gromada J \& Urano F 2011 Endoplasmic reticulum stress and pancreatic cell death. Trends in Endocrinology and Metabolism 22 266-274. (doi:10.1016/j.tem.2011.02.008)

Islam MS \& Loots DT 2009 Experimental rodent models of type 2 diabetes: a review. Methods and Findings in Experimental and Clinical Pharmacology 31 249-261. (doi:10.1358/mf.2009.31.4.1362513)

Janson J, Soeller WC, Roche PC, Nelson RT, Torchia AJ, Kreutter DK \& Butler PC 1996 Spontaneous diabetes mellitus in transgenic mice expressing human islet amyloid polypeptide. PNAS 93 7283-7288. (doi:10.1073/pnas.93.14.7283)

Kahn SE, Hull RL \& Utzschneider KM 2006 Mechanisms linking obesity to insulin resistance and type 2 diabetes. Nature $\mathbf{4 4 4} 840-846$. (doi:10.1038/nature05482)

Leonova KI, Brodsky L, Lipchick B, Pal M, Novototskaya L, Chenchik AA, Sen GC, Komarova EA \& Gudkov AV 2013 p53 cooperates with DNA methylation and a suicidal interferon response to maintain epigenetic silencing of repeats and noncoding RNAs. PNAS 110 89-98. (doi:10.1073/pnas.1216922110)

Li D-S, Yuan Y-H, Tu H-J, Liang Q-L \& Dai L-J 2009 A protocol for islet isolation from mouse pancreas. Nature Protocols 4 1649-1652. (doi:10.1038/nprot.2009.150)

Liadis N, Salmena L, Kwan E, Tajmir P, Schroer SA, Radziszewska A, Li X, Sheu L, Eweida M, Xu S et al. 2007 Distinct in vivo roles of caspase-8 in $\beta$-cells in physiological and diabetes models. Diabetes 56 2302-2311. (doi:10.2337/db06-1771)

Marciniak SJ, Yun CY, Oyadomari S, Novoa I, Zhang Y, Jungreis R, Nagata K, Harding HP \& Ron D 2004 CHOP induces death by promoting protein synthesis and oxidation in the stressed endoplasmic reticulum. Genes and Development 18 3066-3077. (doi:10.1101/gad.1250704)

Mihailidou C, Papazian I, Papavassiliou AG \& Kiaris H 2010 CHOPdependent regulation of p21/waf1 during ER stress. Cellular Physiology and Biochemistry 25 761-766. (doi:10.1159/000315096)

Mihailidou C, Chatzistamou I, Papavassilou AG \& Kiaris H 2010 Improvement of chemotherapeutic drug efficacy by endoplasmic reticulum stress. Endocrine Related Cancer (In Press). (doi:10.1530/ ERC-15-0019) 
Mlynarczyk C \& Fåhraeus R 2014 Endoplasmic reticulum stress sensitizes cells to DNA damage-induced apoptosis through p53-dependent suppression of p21 ${ }^{\mathrm{CDKN1A}}$. Nature Communications 55067. (doi:10.1038/ncomms6067)

Moore CE, Omikorede O, Gomez E, Willars GB \& Herbert TP 2011 PERK activation at low glucose concentration is mediated by SERCA pump inhibition and confers preemptive cytoprotection to pancreatic $\beta$-cells. Molecular Endocrinology 25 315-326. (doi:10.1210/me.2010-0309)

Oyadomari S \& Mori M 2004 Roles of CHOP/GADD153 in endoplasmic reticulum stress. Cell Death and Differentiation 11 381-389. (doi:10.1038/sj.cdd.4401373)

Oyadomari S, Koizumi A, Takeda K, Gotoh T, Akira S, Araki E \& Mori M 2002 Targeted disruption of the Chop gene delays endoplasmic reticulum stress-mediated diabetes. Journal of Clinical Investigation 109 525-532. (doi:10.1172/JCI0214550)

Palorini R, Cammarata FP, Balestrieri C, Monestiroli A, Vasso M, Gelfi C, Alberghina L \& Chiaradonna F 2013 Glucose starvation induces cell death in K-ras-transformed cells by interfering with the hexosamine biosynthesis pathway and activating the unfolded protein response. Cell Death \& Disease 4 e732. (doi:10.1038/cddis.2013.257)

Papa FR 2012 Endoplasmic reticulum stress, pancreatic $\beta$-cell degeneration, and diabetes. Cold Spring Harbor Perspectives in Medicine 2 a007666. (doi:10.1101/cshperspect.a007666)

Puthalakath H, O'Reilly LA, Gunn P, Lee L, Kelly PN, Huntington ND, Hughes PD, Michalak EM, McKimm-Breschkin J, Motoyama N et al. 2007 ER stress triggers apoptosis by activating BH3-only protein Bim. Cell 129 1337-1349. (doi:10.1016/j.cell.2007.04.027)

Ron D 2002 Proteotoxicity in the endoplasmic reticulum: lessons from the Akita diabetic mouse. Journal of Clinical Investigation 10 443-445. (doi:10.1172/JCI0215020)

Ron D \& Habener JF 1992 CHOP, a novel developmentally regulated nuclear protein that dimerizes with transcription factors C/EBP and LAP and functions as a dominant-negative inhibitor of gene transcription. Genes and Development 6 439-453. (doi:10.1101/gad.6. 3.439)

Ron D \& Walter P 2011 The unfolded protein response: from stress pathway to homeostatic regulation. Science 334 1081-1086. (doi:10.1126/ science.1209038)

Roninson IB 2002 Oncogenic functions of tumour suppressor p $21^{\text {Waf } 1 / \text { Cip } 1 / \text { di1 }}$ : association with cell senescence and tumourpromoting activities of stromal fibroblasts. Cancer Letters 1 1-14. (doi:10.1016/S0304-3835(01)00847-3)
Russell JW, Golovoy D, Vincent AM, Mahendru P, Olzmann JA, Mentzer A \& Feldman EL 2002 High glucose-induced oxidative stress and mitochondrial dysfunction in neurons. FASEB Journal 16 1738-1748. (doi:10.1096/fj.01-1027com)

Scheuner D \& Kaufman RJ 2008 The unfolded protein response: a pathway that links insulin demand with $\beta$-cell failure and diabetes. Endocrine Reviews 29 317-333. (doi:10.1210/er.2007-0039)

Secchiero P, Toffoli B, Melloni E, Agnoletto C, Monasta L \& Zauli G 2013 The MDM2 inhibitor Nutlin-3 attenuates streptozotocin-induced diabetes mellitus and increases serum level of IL-12p40. Acta Diabetologia 50 899-906. (doi:10.1007/s00592-013-0476-8)

Timchenko NA, Wilde M, Nakanishi M, Smith JR \& Darlington GJ 1996 $\mathrm{CCAAT} /$ enhancer-binding protein $\alpha(\mathrm{C} / \mathrm{EBP} \alpha)$ inhibits cell proliferation through the $\mathrm{p} 21$ (WAF-1/CIP-1/SDI-1) protein. Genes and Development 10 804-815. (doi:10.1101/gad.10.7.804)

Trimis G, Chatzistamou I, Politi K, Kiaris H \& Papavassiliou AG 2008 Expression of $\mathrm{p} 21^{\mathrm{waf} 1 / \mathrm{Cip} 1}$ in stromal fibroblasts of primary breast tumors. Human Molecular Genetics 17 3596-3600. (doi:10.1093/hmg/ ddn252)

Ubeda M, Wang XZ, Zinszner H, Wu I, Habener JF \& Ron D 1996 Stressinduced binding of the transcriptional factor CHOP to a novel DNA control element. Molecular and Cellular Biology 16 1479-1489.

Vassilev LT, Vu BT, Graves B, Carvajal D, Podlaski F, Filipovic Z, Kong N, Kammlott U, Lukacs C, Klein C et al. 2004 In vivo activation of the p53 pathway by small-molecule antagonists of MDM2. Science $\mathbf{3 0 3}$ 844-848. (doi:10.1126/science.1092472)

Weiss RH 2003 p21 Waf1/Cip1 as a therapeutic target in breast and other cancers. Cancer Cell 6 425-429. (doi:10.1016/S1535-6108(03)00308-8)

Xu C, Bailly-Maitre B \& Reed JC 2005 Endoplasmic reticulum stress: cell life and death decisions. Journal of Clinical Investigation 115 2656-2664. (doi:10.1172/JCI26373)

Yang J, Zhang W, Jiang W, Sun X, Han Y, Ding M, Shi Y \& Deng H 2009

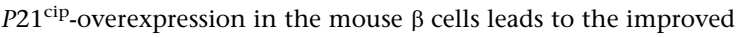
recovery from streptozotocin-induced diabetes. PLoS ONE $\mathbf{4}$ e8344. (doi:10.1371/journal.pone.0008344)

Yi N, Chen SY, Ma A, Chen PS, Yao B, Liang TM \& Liu C 2012 Tunicamycin inhibits PDGF-BB-induced proliferation and migration of vascular smooth muscle cells through induction of HO-1. Anatomical Record 295 1462-1472. (doi:10.1002/ar.22539)

Zinszner H, Kuroda M, Wang X, Batchvarova N, Lightfoot RT, Remotti H, Stevens JL \& Ron D 1998 CHOP is implicated in programmed cell death in response to impaired function of the endoplasmic reticulum. Genes and Development 12 982-995. (doi:10.1101/gad.12.7.982)

Received in final form 6 February 2015

Accepted 10 February 2015

Made available online as an Accepted Preprint

10 February 2015
(C) 2015 Society for Endocrinology Printed in Great Britain 